\title{
Weekly versus Tri-weekly Cisplatin Concurrent with Radiotherapy in the Treatment of Locally Advanced Carcinoma Cervix: A Prospective Study
}

\begin{abstract}
Context: Different schedules of concurrent chemotherapy with definitive radiotherapy in locally advanced carcinoma cervix. Aims: The aim is to evaluate toxicity, compliance, and response of weekly versus tri-weekly cisplatin given concurrently with radiotherapy in locally advanced squamous cell carcinoma cervix. Subjects and Methods: One hundred and ten newly diagnosed histopathologically confirmed squamous cell carcinoma cervix patients with International Federation of Gynecologists and Oncologists stage IIB to IVA were randomly distributed among study group receiving $75 \mathrm{mg} / \mathrm{m}^{2}$ of cisplatin every 3 weeks for three cycles and control group receiving $40 \mathrm{mg} / \mathrm{m}^{2}$ of weekly cisplatin for six cycles. Results: Patients in both the arms tolerated treatment well. At the time of completion of chemoradiotherapy, $83.63 \%$ of patients of the study group and $80 \%$ of the control group had a complete response whereas $16.37 \%$ of study and $20 \%$ of the control group had a partial response, both statistically insignificant $(P>0.05)$. Compliance was similar in both the groups. The average time to complete radiotherapy was 54.63 days in the study group and 51.34 days in the control group. In the study group, $87.27 \%$ of patients completed all cycles of tri-weekly chemotherapy, whereas, in control group, $80 \%$ completed all 6 cycles of weekly chemotherapy. The difference was not statistically significant $(P=0.30)$. Toxicity in terms of vomiting, grade 3-4 leukopenia and neutropenia were more in the study group which was statistically significant $(P<0.001, P=0.04$, and $P=0.03$, respectively). Conclusions: Although the 3 -weekly cisplatin schedule has longer intervals and sounds convenient, the weekly cisplatin regime shows lower hematologic toxicity with similar disease response and compliance.

Keywords: Cervical cancer, concurrent chemoradiation, Cisplatin, external-beam radiotherapy, International Federation of Gynecology and Obstetrics, high dose rate intracavitary brachytherapy
\end{abstract}

\section{Introduction}

Cervical cancer is the second most common cancer diagnosed in women in India. $^{[1]}$ About 122,844 new cervical cancer cases are diagnosed annually in India. ${ }^{[2]}$ At our center, carcinoma cervix is the most common cancer among females. Patients usually present to us with International federation of Gynecology and Obstetrics (FIGO) stage IIB, III and IV; in which Concurrent Chemo-Radiotherapy (CCRT) plays a major role in the management. ${ }^{[3,4]}$

\section{Subjects and Methods}

The present prospective study was carried out at Sawai Man Singh Medical College and attached group of Hospitals, Jaipur, Rajasthan from January 2014 to June 2015 with a median follow up of 33 months. 110 histopathologically confirmed newly diagnosed cases of

This is an open access journal, and articles are distributed under the terms of the Creative Commons Attribution-NonCommercial-ShareAlike 4.0 License, which allows others to remix, tweak, and build upon the work non-commercially, as long as appropriate credit is given and the new creations are licensed under the identical terms.

For reprints contact: reprints@medknow.com squamous cell carcinoma of cervix FIGO stage IIB to IVA with ECOG performance status $0-2$ were randomised into study and control groups, with 55 patients in both groups. All patients were younger than 70 but older than 18 years with hemoglobin $\geq 9 \quad \mathrm{~g} \%$, absolute neutrophil count $>1500 / \mathrm{uL}$, platelet count $>1,00,000 / \mathrm{uL}$, serum creatinine level $<1.4 \mathrm{mg} / \mathrm{dl}$ and serum bilirubin $<2$ times the normal upper unit. Patients with other than squamous pathology, history of previous radiotherapy or surgery for the same malignancy, second malignancy, distant metastasis, other uncontrolled comorbidities, and pregnancy were excluded from the study.

\section{Chemotherapy}

All patients who were enrolled in the study group were planned to receive injection cisplatin with dose of $75 \mathrm{mg} / \mathrm{m}^{2}$

How to cite this article: Sandeep B, Sandeep J, Kartick R, Aseem-Rai B, Neeraj S. Weekly versus tri-weekly cisplatin concurrent with radiotherapy in the treatment of locally advanced carcinoma cervix: A prospective study. Indian J Med Paediatr Oncol 2018;39:467-72.
Bhaskar Sandeep, Jain Sandeep, Rastogi Kartick, Bhatnagar Aseem-Rai', Sharma Neeraj

Department of Radiotherapy, SMS Medical College and Attached Group of Hospitals, ${ }^{1}$ Department of Radiation Oncology, Shalby Hospital, Jaipur, Rajasthan, India
Address for correspondence: Dr. Rastogi Kartick, Department of Radiotherapy, SMS Hospital, Jaipur - 302004 Rajasthan, India.

E-mail: kartickrastogi@gmail. com

Access this article online Website: www.ijmpo.org DOI: 10.4103/ijmpo.ijmpo_89_17 Quick Response Code:

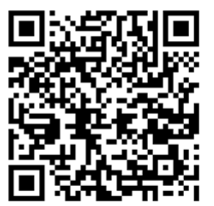


intravenously on day 1,22 , and 43 of radiotherapy, for a total of three courses. Those who were enrolled in the control arm were planned to receive injection cisplatin with dose of $40 \mathrm{mg} / \mathrm{m}^{2}$ intravenously on day $1,8,15,22,29$, and 36 of radiotherapy, for a total of six courses.

\section{Radiotherapy}

Combined external-beam radiotherapy (EBRT) and high dose rate intracavitary brachytherapy (HDR ICBT) was used for the treatment of patients. The primary tumor and regional lymphatics were treated with 45-50.4 Gy in conventional fractionation at 1.8 Gy per fraction over Seimens Oncor Expression Linear Accelerator using three-dimensional conformal radiotherapy technique with 15 MV beam energy. The first HDR ICBT was performed toward the latter part of EBRT when sufficient tumor regression was noted to permit satisfactory applicator geometry. This was usually after the $3^{\text {rd }}$ week of EBRT and additional EBRT was delivered with a central shield. On the day of ICBT, neither EBRT nor chemotherapy was prescribed. The recommended total point A dose combining EBRT with ICBT was 80 Gy for small volume cervical tumors and 85-90 Gy for large volume tumors. To avoid the negative impact of treatment prolongation, the overall treatment time was intended to be kept $<8$ weeks. ${ }^{[5,6]}$

\section{Evaluation of patients}

All patients were clinically examined weekly during the treatment for any complaints. Hemogram and biochemical investigations were performed and noted before giving chemotherapy. The clinical appearance of the primary tumor at the initiation of treatment was noted. The regression of primary tumor during the treatment was assessed and noted biweekly. Any delay causing treatment interruption was also noted and necessary gap correction for radiotherapy was done. Chemotherapy was withheld during radiotherapy interruptions, but radiotherapy was continued in spite of chemotherapy being discontinued due to hematological toxicities. At the completion of treatment and subsequent follow up, the disease response was assessed. The results of study group were analyzed and compared with control group in terms of compliance, toxicities, and tumor response. Response was assessed as per the WHO Criteria. Acute toxicities were assessed as per the Radiation Therapy Oncology Group (RTOG) Acute Radiation Morbidity Scoring criteria. Chemotherapy induced toxicities such as nausea, vomiting, renal and hematological toxicities were assessed as per the CommonTerminology Criteria for Adverse Events (v4.03), National Cancer Institute (USA). Patients were evaluated every month on follow up with detailed clinical examination to assess local disease response and to note any bladder/bowel symptom. Hematological tests and imaging studies were done wherever indicated.

\section{Statistical analysis}

This was an open-label, randomized trial with 1:1 allocation. The randomized assignment was done using a chit in box method with replacement. The categorical clinical characteristics between the two treatments were compared using Chi-square $\left(\chi^{2}\right)$ test. Data were analyzed using Statistical Package for Social Sciences (SPSS) software trial version 20.0 (IBM Corp., Armonk, New York, USA).

\section{Results}

In the present study, the patient and tumor characteristics were identical in the two groups [Table 1]. In both the groups, patients were in the age group of 30-70 and majority of them were in their $4^{\text {th }}$ and $5^{\text {th }}$ decade of life. Mean age of presentation was 49.36 and 49.43 years for study and control group, respectively. More than two-third of the patients belonged to the rural background in both the groups. All the patients included in the study were having ECOG performance status score up to 2. The hemoglobin of all patients included in the study was equal or above $9.0 \mathrm{~g} \%$, mean hemoglobin at presentation was $10.56 \mathrm{~g} \%$ and $10.60 \mathrm{~g} \%$ for study and control group, respectively. Only histopathologically proven squamous cell carcinoma patients were included in this study. The distribution of patients according to the histological differentiation of primary tumor revealed moderately differentiation as the most common pattern of differentiation. Among the study group, $78.2 \%$ and in the control group, $81.8 \%$ had moderately differentiated tumor. The most common stage of presentation was FIGO stage IIB with $54.5 \%$ in the study group and $50.9 \%$ in control group.

Treatment related toxicities are shown in Table 2 and Figure 1. In the study group, 10 patients $(18.2 \%)$ had grade 1 skin reactions as compared to $20(36.4 \%)$ in the control group. $34(61.8 \%)$ and $11(20 \%)$ patients in the study group and $26(42.8 \%)$ and $7(12.7 \%)$ in the control group had grade 2 and grade 3 skin reaction,

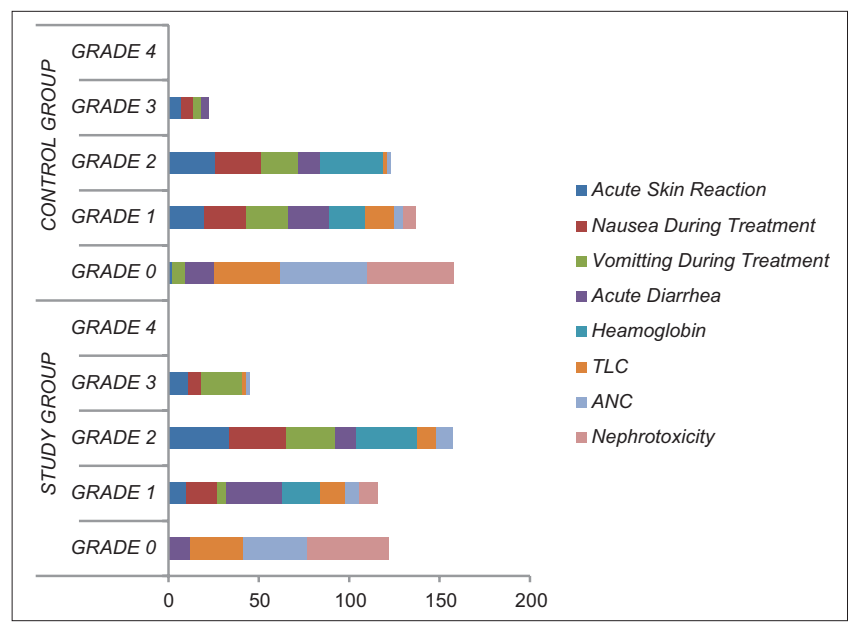

Figure 1: Worst Acute Toxicity During Treatment 


\begin{tabular}{|c|c|c|c|}
\hline & Study group, $n(\%)$ & Control group, $n(\%)$ & $P$ value \\
\hline \multicolumn{4}{|l|}{ Age (years) } \\
\hline$\leq 40$ & 9 & 13 & 0.15 \\
\hline $41-50$ & 25 & 18 & \\
\hline $51-60$ & 16 & 12 & \\
\hline $61-70$ & 5 & 12 & \\
\hline \multicolumn{4}{|l|}{ Geographic distribution } \\
\hline Rural & $38(69)$ & $37(67.3)$ & 0.84 \\
\hline Urban & $17(31)$ & $18(32.7)$ & \\
\hline \multicolumn{4}{|l|}{ ECOG performance status } \\
\hline 0 & 0 & 0 & 0.54 \\
\hline 1 & $50(91)$ & $48(87.3)$ & \\
\hline 2 & $5(9)$ & $7(12.7)$ & \\
\hline \multicolumn{4}{|l|}{ FIGO stage } \\
\hline IIB & $30(54.5)$ & $28(50.9)$ & 0.70 \\
\hline IIIA & $2(3.6)$ & $1(1.9)$ & \\
\hline IIIB & $22(40)$ & $23(41.8)$ & \\
\hline IVA & $1(1.9)$ & $3(5.4)$ & \\
\hline \multicolumn{4}{|c|}{ Differentiation of squamous cell carcinoma } \\
\hline Well differentiated & $10(18.2)$ & $7(12.7)$ & 0.68 \\
\hline Moderately differentiated & $43(78.2)$ & $45(81.8)$ & \\
\hline Poorly differentiated & $2(3.6)$ & $3(5.5)$ & \\
\hline \multicolumn{4}{|c|}{ Duration of radiotherapy (weeks) } \\
\hline$\leq 8$ & 48 & 52 & 0.18 \\
\hline$>8$ & 7 & 3 & \\
\hline
\end{tabular}

ECOG - Eastern cooperative oncology group; FIGO - International federation of gynecology and obstetrics

Table 2: Worst acute toxicity during treatment

\begin{tabular}{|c|c|c|c|c|c|c|c|c|c|c|c|}
\hline \multirow[t]{2}{*}{ Toxicity } & \multicolumn{5}{|c|}{ Study group } & \multicolumn{5}{|c|}{ Control group } & \multirow{2}{*}{$\begin{array}{l}\text { Statistics } \\
P \text { Value }\end{array}$} \\
\hline & Grade 0 & Grade 1 & Grade 2 & Grade 3 & Grade 4 & Grade 0 & Grade 1 & Grade 2 & Grade 3 & Grade 4 & \\
\hline $\begin{array}{l}\text { Acute skin } \\
\text { reaction }\end{array}$ & 0 & 10 & 34 & 11 & 0 & 2 & 20 & 26 & 7 & 0 & 0.06 \\
\hline $\begin{array}{l}\text { Nausea during } \\
\text { treatment }\end{array}$ & 0 & 17 & 31 & 7 & 0 & 0 & 23 & 25 & 7 & 0 & 0.46 \\
\hline $\begin{array}{l}\text { Vomitting } \\
\text { during } \\
\text { treatment }\end{array}$ & 0 & 5 & 27 & 23 & 0 & 7 & 23 & 21 & 4 & 0 & $<0.001$ \\
\hline Acute diarrhea & 12 & 31 & 12 & 0 & 0 & 16 & 23 & 12 & 4 & 0 & 0.12 \\
\hline Heamoglobin & 0 & 21 & 34 & 0 & 0 & 0 & 20 & 35 & 0 & 0 & 0.84 \\
\hline TLC & 29 & 14 & 10 & 2 & 0 & 37 & 16 & 2 & 0 & 0 & 0.04 \\
\hline ANC & 36 & 8 & 9 & 2 & 0 & 48 & 5 & 2 & 0 & 0 & 0.03 \\
\hline Nephrotoxicity & 45 & 10 & 0 & 0 & 0 & 48 & 7 & 0 & 0 & 0 & 0.43 \\
\hline
\end{tabular}

TLC - Total leukocyte counts; ANC - Absolute neutrophil counts

\begin{tabular}{|c|c|c|c|c|c|c|c|c|c|}
\hline \multicolumn{10}{|c|}{ Table 3: Follow-up status } \\
\hline \multirow{2}{*}{$\begin{array}{l}\text { Treatment } \\
\text { response }\end{array}$} & \multicolumn{4}{|c|}{ Study group $(n)$} & \multicolumn{4}{|c|}{ Control group (n) } & \multirow{2}{*}{$\begin{array}{l}\text { Statistics } \\
P \text { value }\end{array}$} \\
\hline & $\begin{array}{l}\text { Complete } \\
\text { response }\end{array}$ & $\begin{array}{c}\text { Partial } \\
\text { response }\end{array}$ & $\begin{array}{c}\text { No } \\
\text { change }\end{array}$ & $\begin{array}{c}\text { Progressive } \\
\text { disease }\end{array}$ & $\begin{array}{l}\text { Complete } \\
\text { response }\end{array}$ & $\begin{array}{c}\text { Partial } \\
\text { response }\end{array}$ & $\begin{array}{c}\text { No } \\
\text { change }\end{array}$ & $\begin{array}{c}\text { Progressive } \\
\text { disease }\end{array}$ & \\
\hline End of treatment & 46 & 9 & 0 & 0 & 44 & 11 & 0 & 0 & 0.63 \\
\hline $\begin{array}{l}6 \text { month } \\
\text { follow up }\end{array}$ & 50 & 5 & 0 & 0 & 50 & 5 & 0 & 0 & 1.00 \\
\hline
\end{tabular}

respectively $(P=0.06)$. For nausea, in the study group $17(30.9 \%)$ of the patients had grade 1 reactions as compared to $23(41.8 \%)$ in the control group. $31(56.4 \%)$ in the study group and $25(45.5 \%)$ in the control group had 
grade 2 reaction. The incidence of grade 3 was $7(12.7 \%)$ and $7(12.7 \%)$ in the study group and control group, respectively $(P=0.46)$. The vomiting during the treatment was more in the study group which was statistically significantly $P<0.001$. In the control group, 30 (54.5\%), $21(38.18 \%)$ and $4(7.27 \%)$ patients had grade 1,2 , and 3 vomiting, respectively, as compared to 5 (9.09\%), $27(49.09 \%)$, and $23(41.8 \%)$ patients in the study group. The incidence of acute diarrhea during treatment was seen more in study group; $31(56.4 \%), 12(21.8 \%)$, and $0(0 \%)$ had grade 1,2 , and 3 , respectively compared to control group having 23 (41.8\%), 12 (21.8\%), and 4 (7.2\%) grade 1, 2, and 3 diarrhea, respectively. There is no statistical difference in incidence of acute diarrhea between the study and control groups $(P=0.12)$.

As far as hematological toxicities are concerned, in the study group $21(38.2 \%)$ had grade 1 and $34(61.8 \%)$ had grade 2 anemia, whereas in control group, $20(36.4 \%)$ had grade 1 and $35(63.6 \%)$ had grade 2 anemia $(P=0.84)$. For total leukocyte counts, study group had more grade $2(10[18.2 \%])$ and grade 3 toxicity (2 [3.6\%]) compared to control group having only $2(3.6 \%)$ grade 2 toxicity. $14(25.5 \%)$ and $16(29.09 \%)$ had grade 1 toxicity in study and control group, respectively. This difference is statistically significant, showing more toxicity in the study group compared to control group, $P=0.04$. Similar to total leucocyte count, absolute neutrophil count showed the same pattern of toxicity profile. $36(65.5 \%)$ and $48(87.3 \%)$ had no toxicity, $8(14.5 \%)$ and $5(9.09 \%)$ had grade 1, $9(16.4 \%)$ and $2(3.6 \%)$ had grade 2 and $2(3.6 \%)$ and none $(0 \%)$ had grade 3 toxicity in the study and control group, respectively. This difference was statistically significant, more in the study group compared to control group $(P=0.03)$. No nephrotoxicity was found in $45(81.8 \%)$ in the study group and $48(87.3 \%)$ in the control group, whereas $10(18.2 \%)$ and $7(12.7 \%)$ were found to have grade 1 toxicity in the study and control group, respectively $(P=0.43)$. The audiometry report of all the patients was comparable to their pretreatment and post treatment reports, i.e., there was no increased hearing loss or ototoxicity found among all the patients in both study and control group.

Compliance of the treatment was defined in terms of completeness of chemotherapy and radiotherapy within the prescribed time limits. The American Brachytherapy Society recommends keeping the total treatment duration to $<8$ weeks, i.e., 56 days. ${ }^{[7]}$ In the study group, the average time of completion of radiotherapy was 54.63 days, (range $=48-81$ days), $48(87.27 \%)$ patients completed their radiotherapy within 56 days (8 weeks) of starting treatment. Whereas in the control group, the average time was 51.34 days, (range $=48-60$ days), $52(94.54 \%)$ patients completed within the prescribed time of 56 days (8 weeks). This difference did not reach statistical significance $(P=0.18)$.
Treatment response of disease of patients was done using the WHO criteria while on treatment and subsequent follow up. At the end of treatment, 46 (83.63\%) of study group and $44(80 \%)$ of control group had complete response (CR), $9(16.37 \%)$ patients of study group and $11(20 \%)$ patients of control group had partial response (PR) $(P=0.62)$. At 6 months after completion of CCRT, both the study and control group had 50 (90.9\%) CR and $5(9.1 \%)$ PR rates $(P=1)$. At last follow up, the disease-free survival was same for both the study and control group [Table 3].

\section{Discussion}

In 1999, five large prospective randomized trials performed by the Gynecologic Oncology Group (GOG), RTOG, and the South-West Oncology Group demonstrated significant survival advantage and superiority in reducing risk of death by $30 \%-50 \%$ in cisplatin-based chemotherapy given concurrently with pelvic radiotherapy when compared to either radiotherapy alone or radiotherapy with concurrent nonplatinum containing chemotherapy. It was stated that cisplatin-based CCRT also decreased the relative risk of recurrence and the mortality. Among the previous five randomized clinical trials, two trials performed by the GOG used weekly cisplatin $40 \mathrm{mg} / \mathrm{m}^{2}$, whereas the other three trials used tri-weekly cisplatin at a dosage range of 50$75 \mathrm{mg} / \mathrm{m}^{2}$ combined with 5-fluorouracil. Although recently reported meta-analysis studies also demonstrated $6 \%$ improvement in 5-year survival with cisplatin-based CCRT, the optimal cisplatin dose and dosing schedule are still undetermined. Hence, in this study, we tried to investigate the response, compliance and toxicity of weekly cisplatin $40 \mathrm{mg} / \mathrm{m}^{2}$ and tri-weekly cisplatin $75 \mathrm{mg} / \mathrm{m}^{2}$ administration concurrent with radiotherapy. ${ }^{[4,8-10]}$

The results of five randomized studies which included nearly 2000 patients were published in 1999, demonstrating that survival rate with CCRT based on cisplatin was superior to that obtained with radiation alone. Afterward, a meta-analysis based on 19 trials (17 published and two unpublished) including 4580 patients corroborated these findings, confirming that chemoradiation offers an absolute survival benefit of $12 \%$ at 5 years. ${ }^{[1]}$ Thus, cisplatin-based CCRT was largely accepted as the standard of care for patients with locally advanced cervical cancer with FIGO stage IB2-IVA, except for patients with comorbidities who are radiated for stage IB1 or less. CCRT also showed significant benefit for local recurrence and the suggestion of a benefit for distant recurrence. Acute hematological and gastrointestinal toxicity was significantly higher in the CCRT group. ${ }^{[12]}$ After years of studying multi-modality treatments as an alternative to radiation alone in randomized phase III trials, the standard treatment has changed to CCRT based on cisplatin. ${ }^{[13]}$ Despite these encouraging results, there remains room for improvement as the 5-year survival of patients treated with CCRT ranges from nearly $80 \%$ in bulky IB tumors to only $25 \%$ in stage IVA disease. 
Kato et al. ${ }^{[14]}$ studied CCRT with weekly cisplatin in locally advanced cervical carcinoma and observed acute grade 3 leukopenia in $21 \%$ of the patients, and grade 3 gastrointestinal toxicity in $6 \%$. No patient failed to complete the radiotherapy course because of toxicity. The 2-year local control and overall survival rate for all patients were $87.1 \%$ and $79.6 \%$, respectively. In this study, they had more toxicity, may be due to less number of patients enrolled in the present study. Ryu et al. ${ }^{[15]}$ in 2010 compared weekly versus tri-weekly cisplatin administered concurrently with radiotherapy in 104 locally advance ca cervix patients. He found that all patients tolerated both treatments very well, with a high completion rate of scheduled chemotherapy cycles. There was no statistically significant difference in compliance between the two arms $(86.3 \%$ in the weekly arm, $92.5 \%$ in the tri-weekly arm, $P>0.05$ ). Grade 3-4 neutropenia was more frequent in the weekly arm (39.2\%) than in the tri-weekly arm $(22.6 \%)(P=0.03)$. The overall 5-year survival rate was significantly higher in the tri-weekly arm (88.7\%) than in the weekly arm (66.5\%) (Hazard ratio 0.375; 95\% confidence interval $0.154-0.914 ; P=0.03)$. So, they concluded that tri-weekly cisplatin $75 \mathrm{mg} / \mathrm{m}^{2}$ chemotherapy concurrent with radiotherapy is more effective and feasible than the conventional weekly cisplatin $40-\mathrm{mg} / \mathrm{m}^{2}$ regimen. Chumworathayi et al.$^{[16]} 2005$ studied compliance of weekly versus 3-weekly cisplatin as an adjunct to radiotherapy in high-risk early stage cervical carcinoma after surgery using $40 \mathrm{mg} / \mathrm{m}^{2}$ as weekly cisplatin dose for 6 cycles and $75 \mathrm{mg} /$ $\mathrm{m}^{2}$ tri-weekly cisplatin for 4 cycles and found statistically significant difference in neutropenia and hearing loss. In the present study, none of the patients had hearing loss, whereas the neutropenia was consistent with the findings. Ikushima et $a l^{[17]}$ in 2006 found severe hematological toxicity in $86 \%$ patients, grade 3 in $81 \%$ patients and grade 4 in $4.8 \%$ patients. Moderate or severe gastrointestinal toxicity occurred in 11 patients (52\%), grade 2 in 10 patients $(48 \%)$, and grade 3 in one patient (4.8\%). All patients completed RT without interruption. This study had higher toxicity as compared to the present study, reason being lesser number of patients enrolled in the study done by them.

In the study, Chumworathayi et al. ${ }^{[16]}$ have found $100 \%$ completion of chemotherapy but with delay in $30.3 \%$ cycles in the 3 weekly group and $12.9 \%$ cycles delay in the weekly group, which is statistically not significant. In their study, they have found that all patients completed their radiotherapy within time, the time frame in their study to complete radiotherapy was 10 weeks. This finding of chemotherapy completion was not consistent with the study. Although their study showed better compliance in the weekly group, it was not statistically significant. Moreover, their time period of completion of radiotherapy was 10 weeks which is different from the recommended duration of 8 weeks.

In a study by Kim et al. ${ }^{[18]}$, full planned CCRT was delivered to $55(71 \%)$ patients. The incidence of acute grade $3 / 4$ hematologic toxicity was $26 \%$. The $\mathrm{CR}$ rate was $91 \%$. Four-year overall and progression-free survival rates were $67 \%$ and $66 \%$, respectively, these results are consistent with results of the present study. Toita et al. ${ }^{[19]}$ reported grade $3 / 4$ leukopenia as the most common acute side effect (83\%). The actuarial 3-year pelvic control rate, disease-free survival rate, and overall survival rate were $91 \%, 67 \%$, and $79 \%$, respectively; these results are consistent with the result of the present study.

\section{Conclusion}

The present study shows that weekly cisplatin concurrent with radiotherapy is feasible and has same compliance and response rates as compared with tri-weekly cisplatin in patients with locally advanced cervical cancer. Despite the small number of patients in this single institutional study, there were statistically significant differences in vomiting and grade 3-4 leucopenia and neutropenia, associated more with tri-weekly cisplatin compared to weekly cisplatin.

\section{Financial support and sponsorship}

Nil.

\section{Conflicts of interest}

There are no conflicts of interest.

\section{References}

1. National cancer registry programme, Indian council of medical research, three year report of population based cancer registries 2012-2014, Incidence, Distribution, Trends in Incidence Rates and Projections of Burden of Cancer, Bengluru:India 2016;2:p.926. Available from: http://www.ncrpindia.org/ALL_NCRP REPORTS/PBCR REPORT 2012 2014/ALL CONTENT/PDF Printed_Version/Chapter2_Printed.pdf. [Last accessed on $201 \overline{7}$ Jul 15].

2. Ferlay J, Soerjomataram I, Ervik M, Dikshit R, Eser S, Mathers C, et al. GLOBOCAN 2012 v1.0, Cancer Incidence and Mortality Worldwide: IARC CancerBase No. 11 [Internet]. Lyon, France: International Agency for Research on Cancer; 2013. Available from: http://www.globocan.iarc.fr/factsheet.asp. [Last accessed on 2017 Oct 17].

3. Viswanathan AN. Uterine Cervix. In: Halperin EC, Wazer DE, Perez CA, Brady LW, editor. Principles and practice of radiation oncology, $6^{\text {th }}$ ed. Philadelphia: Lippincott Williams and Wilkins; 2013. p. 1355-9.

4. Rose PG, Bundy BN, Watkins EB, Thigpen JT, Deppe G, Maiman MA, et al. Concurrent cisplatin-based radiotherapy and chemotherapy for locally advanced cervical cancer. N Engl J Med 1999;340:1144-53.

5. Perez CA, Grigsby PW, Castro-Vita H, Lockett MA. Carcinoma of the uterine cervix. I. Impact of prolongation of overall treatment time and timing of brachytherapy on outcome of radiation therapy. Int J Radiat Oncol Biol Phys 1995;32:1275-88.

6. Chen SW, Liang JA, Yang SN, Ko HL, Lin FJ. The adverse effect of treatment prolongation in cervical cancer by high-dose-rate intracavitary brachytherapy. Radiother Oncol 2003;67:69-76.

7. Nag S, Erickson B, Thomadsen B, Orton C, Demanes JD, Petereit D. The American Brachytherapy Society recommendations for high-dose-rate brachytherapy for carcinoma of the cervix. Int J Radiat Oncol Biol Phys 2000;48:201-11. 
8. Keys HM, Bundy BN, Stehman FB, Muderspach LI, Chafe WE, Suggs CL $3^{\text {rd }}$, et al. Cisplatin, radiation, and adjuvant hysterectomy compared with radiation and adjuvant hysterectomy for bulky stage IB cervical carcinoma. N Engl J Med 1999;340:1154-61.

9. Morris M, Eifel PJ, Lu J, Grigsby PW, Levenback C, Stevens RE, et al. Pelvic radiation with concurrent chemotherapy compared with pelvic and para-aortic radiation for high-risk cervical cancer. N Engl J Med 1999;340:1137-43.

10. Whitney CW, Sause W, Bundy BN, Malfetano JH, Hannigan EV, Fowler WC Jr., et al. Randomized comparison of fluorouracil plus cisplatin versus hydroxyurea as an adjunct to radiation therapy in stage IIB-IVA carcinoma of the cervix with negative para-aortic lymph nodes: A Gynecologic Oncology Group and Southwest Oncology Group study. J Clin Oncol 1999; 17:1339-48.

11. Green JA, Kirwan JM, Tierney JF, Symonds P, Fresco L, Collingwood M, et al. Survival and recurrence after concomitant chemotherapy and radiotherapy for cancer of the uterine cervix: A systematic review and meta-analysis. Lancet 2001;358:781-6.

12. Green J, Kirwan J, Tierney J, Vale C, Symonds P, Fresco L, et al. Concomitant chemotherapy and radiation therapy for cancer of the uterine cervix. Cochrane Database Syst Rev 2005;3:CD002225.

13. Serkies K, Jassem J. Concurrent weekly cisplatin and radiotherapy in routine management of cervical cancer: A report on patient compliance and acute toxicity. Int J Radiat Oncol Biol Phys 2004;60:814-21.
14. Kato S, Ohno T, Thephamongkhol K, Chansilpa Y, Yuxing Y, Devi CR, et al. Multi-institutional phase II clinical study of concurrent chemoradiotherapy for locally advanced cervical cancer in East and Southeast Asia. Int J Radiat Oncol Biol Phys 2010;77:751-7.

15. Ryu SY, Lee WM, Kim K, Park SI, Kim BJ, Kim MH, et al. Randomized clinical trial of weekly vs. triweekly cisplatin-based chemotherapy concurrent with radiotherapy in the treatment of locally advanced cervical cancer. Int J Radiat Oncol Biol Phys 2011;81:e577-81.

16. Chumworathayi B, Suprasert P, Charoenkwan K, Srisomboon J, Phongnarisorn C, Siriaree S, et al. Weekly versus three-weekly cisplatin as an adjunct to radiation therapy in high-risk stage I-IIA cervical cancer after surgery: A randomized comparison of treatment compliance. J Med Assoc Thai 2005;88:1483-92.

17. Ikushima H, Osaki K, Furutani S, Yamashita K, Kawanaka T, Kishida $\mathrm{Y}$, et al. Chemoradiation therapy for cervical cancer: Toxicity of concurrent weekly cisplatin. Radiat Med 2006;24:115-21.

18. Kim YS, Shin SS, Nam JH, Kim YT, Kim YM, Kim JH, et al. Prospective randomized comparison of monthly fluorouracil and cisplatin versus weekly cisplatin concurrent with pelvic radiotherapy and high-dose rate brachytherapy for locally advanced cervical cancer. Gynecol Oncol 2008;108:195-200.

19. Toita T, Moromizato H, Ogawa K, Kakinohana Y, Maehama T, Kanazawa $\mathrm{K}$, et al. Concurrent chemoradiotherapy using high-dose-rate intracavitary brachytherapy for uterine cervical cancer. Gynecol Oncol 2005;96:665-70. 